\title{
Assessing the delivery of alcohol screening and brief intervention in sexual health clinics in the north east of England
}

\author{
C. Sullivan ${ }^{1,2}$, N. Martin ${ }^{3}$, C. White ${ }^{4}$ and D. Newbury-Birch $5^{*}$
}

\begin{abstract}
Background: Risky drinking is associated with risky sexual experiences, however the relationship between alcohol and sex is complex. The aim of the study was to assess the feasibility of delivering alcohol screening and brief interventions in genitourinary medicine (GUM) clinics. The objectives were to; understand the levels of alcohol use amongst patients; report on the number of alcohol interventions delivered; and to analyse the relationship between alcohol use with demographic data as well as diagnosed sexually transmitted infections (STIs) to see if there were any associations.
\end{abstract}

Methods: All new patients attending GUM between April 2012 and March 2013 self-completed the Alcohol Use Disorder Identification Test (AUDIT) prior to their clinical consultation. Where appropriate (scoring 8+ on AUDIT) the clinician would deliver up to 2-3 min of alcohol brief intervention. Descriptive statistics, t-tests, ANOVA and logistic regression were carried out as appropriate.

Results: AUDIT scores were available for 90\% of all new patients (3058/3390) with an average mean score of 7.75. Of those who drank alcohol, $44 \%$ were categorised as being AUDIT positive, including $2 \%$ who had a score indicative of probable alcohol dependence (20+). $55 \%(n=638)$ of patients who screened positive on the AUDIT received a brief intervention whilst $24 \%(n=674)$ of drinkers were diagnosed with a STI. Logistic regression modelling revealed that males, younger age groups and those of 'white' ethnicity were more likely to score positive on AUDIT. Patients classified as non-students, living in deprivation quintiles one to four and categorised as probable alcohol dependence on the AUDIT were more likely to be diagnosed with an STI.

Conclusion: It is possible to embed alcohol screening into routine practice within sexual health services however further work is required to embed brief interventions particularly amongst increasing risk drinkers. If resources are limited, services may consider more targeted rather than universal alcohol screening to specific population groups. The study was undertaken in one GUM service in the North East of England and therefore findings may not be generalizable. The study did not assess efficacy of alcohol brief intervention in this setting.

Keywords: Sexual health clinics, Sexual behaviour, Alcohol, Alcohol screening

\footnotetext{
* Correspondence: d.newbury-birch@tees.ac.uk

${ }^{5}$ School of Health and Social Care, Teesside University, Constantine Building,

Middlesbrough TS1 3BA, UK

Full list of author information is available at the end of the article
}

(c) The Author(s). 2017 Open Access This article is distributed under the terms of the Creative Commons Attribution 4.0 International License (http://creativecommons.org/licenses/by/4.0/), which permits unrestricted use, distribution, and reproduction in any medium, provided you give appropriate credit to the original author(s) and the source, provide a link to the Creative Commons license, and indicate if changes were made. The Creative Commons Public Domain Dedication waiver (http://creativecommons.org/publicdomain/zero/1.0/) applies to the data made available in this article, unless otherwise stated. 


\section{Introduction}

In the United Kingdom (UK), the costs related to alcohol are $€ 25 \mathrm{bn}$ ( $£ 21 \mathrm{bn}$ ) a year for health, welfare, employment, and criminal justice sectors as a consequence of alcohol attributable disease, injury, and violence [1]. Alcohol contributes substantially to the global burden of disease and is responsible for 2.3 million premature deaths worldwide, many of which are preventable [2]. Hazardous drinking is a repeated pattern of drinking that increases the risk of physical or psychological problems, [3] whereas harmful drinking is defined by the presence of these problems [4]. Drinking at hazardous or harmful levels are often categorised as risky drinking.

Risky drinking is also associated with risky sexual experiences. However the relationship between alcohol and sex is complex. Whilst alcohol is not directly involved in disease transmission [5] some studies from the UK $[6,7]$, Europe [8], and the USA [9-11] have found that it can be used to increase confidence, increase sexual arousal, enhance sexual experience, reduce inhibition, impair sexual decision-making and promote sexual behaviour. Some studies have also found that alcohol is associated with having multiple sexual partners [12], having unprotected sex, leading to higher levels of sexually transmitted infections (STIs) $[5,13,14]$ and having sex that is later regretted [8]. Studies undertaken in sexual health clinics in the UK have also found that the levels of alcohol misuse are higher compared to the general population $[15,16]$. However, methodological limitations exist in studies assessing the relationship between alcohol and sexual behaviour (including sexual assault) as there are no standardised measures and definitions for capturing both alcohol consumption (e.g. self-reported, frequency over time which can lead to recall bias) and sexual risk (e.g. condom use, all contraceptive use, number of sexual partners). No direct causal relationship has been proven $[14,17]$ however correlation has been demonstrated $[13,18,19]$.

\section{Alcohol screening and brief intervention}

Screening the adult population for risky drinking and providing feedback and brief intervention (BI) results in a reduction in the amount consumed in one in seven people [20]. The National Institute for Health and Care Excellence (NICE) recommends using the Alcohol Use Disorders Identification Tool (AUDIT) in the guidelines on alcohol-use disorders: preventing harmful drinking Public Health 24 [21, 22].

Brief interventions are not simply traditional psychotherapy delivered in a short duration of time [23, 24]. Typically they are applied to opportunistic, non-treatment seeking populations, delivered by practitioners other than addiction specialists. They largely consists of two different approaches [22]: simple structured advice which, following screening, seeks to raise awareness through the provision of personalised feedback and advice on practical steps to reduce drinking behavior and its adverse consequences; and extended brief intervention which generally involves behaviour change counselling. Extended BI introduces and evokes change by giving the patient the opportunity to explore their alcohol use as well as their motivations and strategies for change. Both forms of BI share the common aim of helping people to change drinking behavior to promote health but they vary in the precise means by which this is achieved. Typically, BIs aim to reduce alcohol consumption rather than achieve abstinence. There is a wide variation in the duration and frequency of brief alcohol interventions, however, they are typically delivered in a single session or a series of related sessions (not exceeding five sessions), lasting between two and $60 \mathrm{~min}$ [20]. They can be implemented by a range of practitioners in a wide variety of settings [25].

Between 20 and $30 \%$ of the population screened in primary care settings [26] and hospital settings [27] have been shown to be risky drinkers. Furthermore, it has been shown that $66 \%$ of women accessing emergency hormonal contraception in community pharmacies are risky drinkers [28].

\section{Background}

In 2010/11 public health quality indicators were included within the contract of a local acute hospital in the North East of England as part of the Commissioning for Quality and Innovation Scheme. Given the perceived relationship between alcohol and sex, local public health strategies were keen to explore interventions to tackle multiple risk behaviours. Consequently all members of staff working in the local genitourinary medicine (GUM) clinics were trained on how to complete the AUDIT and in the delivery of BI (including brief advice and extended BI). This training was based on training previously used in primary care and accident and emergency departments in England [29, 30]. The service compromised of two clinics; one of the clinics was located within a large university city and the second clinic was located within a market town serving a large rural area.

The aim of the study was to assess the feasibility of delivering alcohol screening and BI in GUM clinics.

The objectives were:

1 to understand the levels of alcohol consumption for new patients attending the GUM clinics.

2 to report on the number of BI's delivered as a result of a positive score following alcohol screening and whether this varied for different groups.

3 to analyse the relationship between Alcohol Use Disorders Identification Tool (AUDIT) score with age, deprivation, gender, ethnicity, sexual orientation, student identity and STI's to see if there were any associations. 


\section{Methods}

All new patients from the two clinics were provided with an AUDIT questionnaire to self-complete prior to clinical consultation. The form was modified to include a brief statement that this was part of an overall health assessment and the ability to offer access to relevant alcohol treatment services as required. The form also included pictorial examples of units of alcoholic drinks to help self-completion. The back of the form contained space for subsequent AUDIT assessments and comments for patients returning to the clinic. Patients were brought into the clinical room by a health care worker where basic demographics were checked to confirm patient identity and a brief description of what to expect was given along with a request to self-complete the AUDIT questionnaire prior to the clinician attending.

The clinician seeing the patient would routinely check and score the AUDIT form as part of the clinical assessment. Where appropriate (indicated by scoring $8+$ on the AUDIT) the clinician would deliver up to 2-3 min of BI outlining the possible consequences of excessive alcohol consumption and the relationship with sexual risks. Where appropriate a referral or information about a self-referral would be initiated to the alcohol liaison nurse based within the hospital. This was not offered to patients who identified they were already in contact with alcohol treatment services.

This current study reviewed AUDIT results for all new attendances for the period of April 2012 to March 2013. The AUDIT is considered to be the gold standard for alcohol screening in health care settings [31]. The AUDIT can be scored between 0 and 40. A score of $8+$ is referred to as a 'positive screen' and indicates an alcohol use disorder; hazardous drinking/increasing risk drinking (score of 8-15), harmful drinking/high risk drinking (16-19) or probable dependent drinking (20+). A score of 8 or more out of a possible 40 on the AUDIT is able to detect genuine excessive drinkers (sensitivity) and to exclude false cases (specificity), and is $92 \%$ and $94 \%$, respectively [21].

Other data collected included age, gender, sexual orientation, student status, infection details, STI tests performed, postcode of residence and positive diagnoses of STIs and infections. The STIs and infections included chlamydia; gonorrhoea; syphilis; genital herpes; genital warts; HIV; hepatitis B; hepatitis C; trichomoniasis; molluscum contagiosum; pelvic inflammatory disease (PID) and epididymitis. Using the National Statistics Postcode Lookup (ONS) patient postcodes [32] were assigned to a Lower Super Output Area (LSOA) and then in turn to a national deprivation quintile as defined by the 2010 Index of Multiple Deprivation (DCLG) [33]. As nearly half (46\%) of LSOAs within the North East fall with the top $30 \%$ of most deprived LSOAs nationally, national deprivation quintiles were re- ranked within the North East region to make analyses more representative of local inequalities. A total of 51 patients were not assigned a deprivation quintile due to their recorded postcode not matching with North East postcodes included in the August 2014 postcode lookup file used at time of analysis.

\section{Data management}

The healthcare assistants extracted data onto a standard template (Excel spreadsheet) for each patient. A reference list of patient case details was created from electronically stored records, which included case identification, demographic information, infection, testing codes and postcode of residence. Using the case ID number, hospital staff were able to reference AUDIT scores held in paper records and update the central spreadsheet.

\section{Data analysis}

Results were analysed using SPSS v22. Descriptive statistics were used in order to characterise mean AUDIT scores for demographics such as age, gender and deprivation quintile. Statistical comparisons for mean AUDIT score were carried out using t-tests ( $\mathrm{t}$-values) in the case of two groups or ANOVA ( $F$ values) for more than two groups with Turkey's Honestly Significant Difference test being used for post-hoc analyses to isolate group differences. Pearson chi-square $\left(\chi^{2}\right)$ was used to test for significant differences between groups testing positive for any STI.

Three logistic regression models were created. Model 1 explored association between gender, age, student status, sexual orientation, ethnicity, deprivation and the odds ratios (OR) of being classified as AUDIT positive (8+). Model 2 looked at the same demographic variables as model 1 and introduced drinking risk group (as defined by AUDIT) to explore the ORs of being offered a BI. Model 3 explored the same demographic variables as model 2 in order to explore the ORs of being diagnosed with a STI. Only the patients who drank (scoring at least one or more on AUDIT) were included in models 1 and 3 whilst model 2 only considered patients who scored positive on AUDIT.

\section{Results}

A total of 3390 new patients accessed the two GUM clinics from April 2012 to March 2013. Of these 47\% were male $(n=1602)$ and $53 \%$ female $(n=1788) .9 \%$ of patients were under the age of $18(n=301), 14 \%$ were aged $18-19(n=488), 34 \%$ were $20-24(n=1136), 14 \%$ were $25-29(n=484)$, $9 \%$ were $30-34(n=289), 6 \%$ were $35-39(n=200)$ and $15 \%$ were aged $40+(n=490)$.

The majority (97\%) of patients were of white ('British', 'Irish' or 'other') ethnic origin (97\% $(n=1548)$ males, $97 \%(n=1731)$ females) and $95 \%$ gave their sexual orientation as being 'heterosexual' (92\% $(n=1472)$ males, $99 \%$ 
( $n=1763$ ) females). $20 \%$ of patients defined themselves as a 'student' (20\% ( $n=327)$ males, $28 \%$ ( $n=507)$ females).

Deprivation quintiles were obtainable for $98 \%(n=3339)$ of patients ( $1=$ most deprived, $5=$ least deprived). $13 \%$ of patients were assigned to quintile one $(n=445), 20 \%$ to quintile two $(n=674), 23 \%$ to quintile three $(n=763), 16 \%$ to quintile four $(n=522)$ and $28 \%$ to quintile five $(n=935)$.

$74 \%$ of patients $(n=2495)$ received the full sexual health screen for chlamydia, gonorrhoea, syphilis and HIV (81\% $(n=1290)$ males, 67\% $(n=1205)$ females. The three most common diagnosed STIs were genital warts: $12.5 \%$ $(n=423)$; chlamydia: $7.8 \%(n=265)$; and genital herpes: $3.7 \%(n=125)$.

\section{AUDIT scores}

Full AUDIT scores were recorded for $90 \%$ of patients $(n=3058) .7 \%$ reported that they did not drink alcohol ( $7 \%$ males and $11 \%$ females). Of those patients who drank alcohol, 44\% were categorised as being AUDIT positive (score of $8+)(53 \%(n=686)$ males, $35 \%(n=526)$ females) including $2 \%$ being categorised as having a score indicative of probable alcohol dependence (3\% $(n=43)$ males, $2 \%(n=26)$ females). Table 1 shows AUDIT scores broken down by age, gender, student status, sexual orientation, ethnicity and deprivation quintile. There were significant differences between mean AUDIT scores within all six of these different demographic groups with males, those aged 20-24 years, students, homosexual/bisexual patients, those who identify as white ethnic origin and people living in the least deprived quintile more likely to have a higher AUDIT score.

Logistic regression results showed that when controlling for other demographics, males were 2.2 times more likely ( $\mathrm{B}=0.785, p<0.0005)$ to score positive on AUDIT when compared with females. The 18-19, 20-24 and 25-29 age groups were all significantly more likely to score positive

Table 1 Mean AUDIT score and numbers of drinkers broken down by drinking risk group

\begin{tabular}{|c|c|c|c|c|c|c|c|c|c|c|}
\hline \multirow[t]{2}{*}{ Demographic group } & \multirow[t]{2}{*}{ Drinkers $\mathrm{N}$} & \multicolumn{3}{|l|}{ AUDIT } & \multicolumn{2}{|c|}{ Low risk $(0-7)$} & \multicolumn{2}{|c|}{ AUDIT positive (8-40) } & \multicolumn{2}{|c|}{ Probably dependent $(20+)$} \\
\hline & & Mean & SD & Range & $\mathrm{N}$ & $\%$ & $\mathrm{~N}$ & $\%$ & $\mathrm{~N}$ & $\%$ \\
\hline Males & 1297 & 8.79 & 5.10 & $1-40$ & 611 & $47 \%$ & 686 & $53 \%$ & 43 & $3 \%$ \\
\hline Females & 1483 & 6.83 & 4.19 & $1-35$ & 957 & $65 \%$ & 526 & $35 \%$ & 26 & $2 \%$ \\
\hline \multicolumn{11}{|c|}{ Significant difference between gender: $t=11.00, p<0.0005$} \\
\hline Under 18 & 236 & 7.15 & 5.46 & $1-35$ & 159 & $67 \%$ & 77 & $33 \%$ & 10 & $4 \%$ \\
\hline $18-19$ & 411 & 8.46 & 4.43 & $1-36$ & 198 & $48 \%$ & 213 & $52 \%$ & 9 & $2 \%$ \\
\hline $20-24$ & 964 & 8.50 & 4.79 & $1-36$ & 452 & $47 \%$ & 512 & $53 \%$ & 28 & $3 \%$ \\
\hline $25-29$ & 409 & 7.55 & 4.83 & $1-28$ & 252 & $62 \%$ & 157 & $38 \%$ & 13 & $3 \%$ \\
\hline 30-34 & 237 & 7.20 & 4.64 & $1-30$ & 149 & $63 \%$ & 88 & $37 \%$ & 7 & $3 \%$ \\
\hline 35-39 & 159 & 6.65 & 3.92 & $1-19$ & 107 & $67 \%$ & 52 & $33 \%$ & 0 & $0 \%$ \\
\hline $40+$ & 364 & 6.40 & 4.23 & $1-40$ & 251 & $69 \%$ & 113 & $31 \%$ & 2 & $1 \%$ \\
\hline \multicolumn{11}{|c|}{ Significant difference between age groups: $F=13.60, p<0.0005$} \\
\hline Non-student & 2064 & 7.61 & 4.89 & $1-40$ & 1212 & $59 \%$ & 852 & $41 \%$ & 57 & $3 \%$ \\
\hline Student & 716 & 8.14 & 4.26 & $1-27$ & 356 & $50 \%$ & 360 & $50 \%$ & 12 & $2 \%$ \\
\hline \multicolumn{11}{|c|}{ Significant difference between student status: $t=-2.74, p=0.006$} \\
\hline Heterosexual & 2649 & 7.69 & 4.69 & $1-40$ & 1505 & $57 \%$ & 1144 & $43 \%$ & 63 & $2 \%$ \\
\hline Other & 131 & 8.82 & 5.47 & $1-35$ & 63 & $48 \%$ & 68 & $52 \%$ & 6 & $5 \%$ \\
\hline \multicolumn{11}{|c|}{ Significant difference between sexual orientation: $t=-2.67, p=0.008$} \\
\hline White & 2706 & 7.80 & 4.74 & $1-40$ & 1517 & $56 \%$ & 1189 & $44 \%$ & 69 & $3 \%$ \\
\hline Black/minority/ethnic & 74 & 5.92 & 4.41 & $1-19$ & 51 & $69 \%$ & 23 & $31 \%$ & 0 & $0 \%$ \\
\hline \multicolumn{11}{|c|}{ Significant difference between ethnicity: $t=3.37, p=0.001$} \\
\hline Deprivation quintile 1 & 357 & 7.71 & 5.30 & $1-35$ & 212 & $59 \%$ & 145 & $41 \%$ & 13 & $4 \%$ \\
\hline Deprivation quintile 2 & 553 & 7.69 & 4.91 & $1-32$ & 321 & $58 \%$ & 232 & $42 \%$ & 17 & $3 \%$ \\
\hline Deprivation quintile 3 & 609 & 7.46 & 4.85 & $1-35$ & 369 & $61 \%$ & 240 & $39 \%$ & 17 & $3 \%$ \\
\hline Deprivation quintile 4 & 435 & 7.43 & 4.74 & $1-39$ & 254 & $58 \%$ & 181 & $42 \%$ & 11 & $3 \%$ \\
\hline Deprivation quintile 5 & 789 & 8.16 & 4.23 & $1-30$ & 397 & $50 \%$ & 392 & $50 \%$ & 11 & $1 \%$ \\
\hline \multicolumn{11}{|c|}{ Significant difference between deprivation quintiles ( $1=$ most deprived): $\mathrm{F}=-2.53, p=0.039$} \\
\hline Total & 2780 & 7.75 & 4.74 & $1-40$ & 1568 & $56 \%$ & 1212 & $44 \%$ & 69 & $2 \%$ \\
\hline
\end{tabular}


on AUDIT when compared to the 40 plus age group with odds ratios of 2.9 ( $\mathrm{B}=1.047, p<0.0005), 2.8(\mathrm{~B}=1.029$, $p<0.0005)$ and $1.5(\mathrm{~B}=0.429, p=0.006)$ respectively. Patients of 'white' ethnicity were also 2.1 times more likely to score positive $(\mathrm{B}=0.738, p=0.006)$ compared to 'other' ethnic groups. There were no significant ORs present between student status, sexual orientation or deprivation quintile. The full model output is shown in Table 2.

\section{Intervention recorded as a result of the AUDIT score}

Of the 1212 patients scoring positive on AUDIT, 1\% $(n=12)$ were already in contact with alcohol treatment services (1\%). Of the remaining 1200 , it was recorded that $53 \%(n=638)$ were offered a brief intervention; $49 \%(n=502)$ of increasing risk drinkers; $80 \%(n=86)$ of high risk drinkers and $82 \%(n=50)$ of probable dependent drinkers. Of those patients offered a brief intervention $9 \%(n=81)$ were further offered a referral to alcohol treatment services and declined whilst 3\% $(n=24)$ accepted a referral to an alcohol treatment

Table 2 Logistic regression model output for relationships between demographics and a positive score on AUDIT

\begin{tabular}{|c|c|c|c|c|}
\hline & Odds ratio & P & Low 95\% & Up 95\% \\
\hline Males & 2.193 & $<0.0005^{a}$ & 1.864 & 2.58 \\
\hline \multicolumn{5}{|l|}{ Females $^{R}$} \\
\hline Under 18 & 1.354 & 0.11 & 0.934 & 1.964 \\
\hline $18-19$ & 2.85 & $<0.0005^{\mathrm{a}}$ & 2.061 & 3.941 \\
\hline $20-24$ & 2.799 & $<0.0005^{\mathrm{a}}$ & 2.122 & 3.692 \\
\hline $25-29$ & 1.536 & $0.006^{a}$ & 1.128 & 2.093 \\
\hline $30-34$ & 1.41 & 0.06 & 0.985 & 2.018 \\
\hline $35-39$ & 1.201 & 0.384 & 0.795 & 1.814 \\
\hline \multicolumn{5}{|l|}{$40+{ }^{R}$} \\
\hline \multicolumn{5}{|l|}{ Non-student ${ }^{R}$} \\
\hline Student & 1.076 & 0.524 & 0.859 & 1.347 \\
\hline \multicolumn{5}{|l|}{ Heterosexual $^{\mathrm{R}}$} \\
\hline Other & 1.118 & 0.555 & 0.772 & 1.621 \\
\hline White & 2.092 & $0.006^{a}$ & 1.235 & 3.545 \\
\hline \multicolumn{5}{|l|}{ Black/minority/ethnic ${ }^{R}$} \\
\hline \multicolumn{5}{|l|}{ Deprivation quintile $1^{R}$} \\
\hline Deprivation quintile 2 & 1.054 & 0.714 & 0.796 & 1.394 \\
\hline Deprivation quintile 3 & 0.993 & 0.959 & 0.753 & 1.309 \\
\hline Deprivation quintile 4 & 1.041 & 0.792 & 0.774 & 1.4 \\
\hline Deprivation quintile 5 & 1.221 & 0.17 & 0.918 & 1.624 \\
\hline
\end{tabular}

service. Logistic regression results revealed that the likelihood of being offered a BI was only significant for different drinking risk groups and not for any other demographic factors. Compared to increasing risk drinkers, higher risk drinkers were 4.7 times more likely to receive a $\mathrm{BI}$ (CI: $2.7-8.0, \quad B=1.538, p<0.0005$ ), whilst probably dependent drinkers were 4.6 times more likely (CI: 2.3-9.3, $\mathrm{B}=1.527, p<0.0005$ ).

\section{Positive diagnoses for an STI}

$24 \%$ of patients $(n=674)$ who drank alcohol were diagnosed with an STI. Chi-square tests revealed that there were significant differences for drinkers being diagnosed with an STI by student status ( $2=18.580, p<0.0005)$ and deprivation status $\left(\chi^{2}=24.255, p<0.0005\right)$. Logistic regression results showed that when controlling for demographics and drinking behaviour non-students were significantly more likely to be diagnosed with an STI with ORs of $1.6(\mathrm{~B}=0.44, p=0.001)$ when compared to students. Patients classed as living in quintiles one to four were also significantly more likely to be diagnosed with an STI when compared to those living in the least deprived quintile with ORs of 1.5 for quintiles one to three and 1.4 for quintile four. There were no significant ORs present between gender, age, sexual orientation or ethnicity. However, people categorised as probably dependent on AUDIT were 1.7 times $(\mathrm{B}=0.53, p=0.041)$ more likely than low risk drinkers to be diagnosed with an STI. The full model output is shown in Table 3.

\section{Discussion}

This study set out to understand the levels of alcohol consumption of patients attending GUM clinics and adds to the literature, that patients attending sexual health clinics have higher levels of alcohol consumption than found in the general population. Furthermore, this study also identified significantly higher AUDIT scores in specific population groups accessing the sexual health service including men, those aged $20-24$ years, students, homosexual/bi-sexual patients, those from a white ethnic origin and people living in the least deprived areas. Only $2 \%$ of patients in this study had a score indicative of probable alcohol dependence $(3 \%(n=43)$ males, $2 \%(n=26)$ females) which is similar to the general population within the same geographical area [34].

The results also show that alcohol screening has been embedded into routine practice within the GUM clinics of study with $90 \%$ of patients recorded as being screened and information recorded systematically into patient records which is far greater to what has been found in other healthcare settings [35]. However, not all patients who scored positive on the AUDIT are recorded as having received a $\mathrm{BI}$, in particular increasing risk drinkers (hazardous drinkers) who may have benefitted from such an 
Table 3 Positive STI bivariate associations and logistic regression model output for relationships between demographics and a positive STI diagnosis (all drinkers)

\begin{tabular}{|c|c|c|c|c|c|c|}
\hline & $\mathrm{N}$ & $\%$ testing positive for any STI & Odds ratio & $P$ & Low 95\% & Up 95\% \\
\hline$\overline{\text { Males }^{R}}$ & 1297 & $25 \%$ & & & & \\
\hline Females & 1483 & $23 \%$ & 0.901 & 0.265 & 0.749 & 1.083 \\
\hline
\end{tabular}

No significant difference between gender and \% testing positive for any STI: $X 2=1.665, p=0.106$

$\begin{array}{lll}\text { Under } 18^{R} & 236 & 26 \% \\ 18-19 & 411 & 24 \% \\ 20-24 & 964 & 26 \% \\ 25-29 & 409 & 25 \% \\ 30-34 & 237 & 22 \% \\ 35-39 & 159 & 20 \% \\ 40+ & 364 & 23 \%\end{array}$

$\begin{array}{llll}1.077 & 0.701 & 0.738 & 1.571 \\ 1.057 & 0.748 & 0.756 & 1.477 \\ 0.851 & 0.404 & 0.583 & 1.243 \\ 0.687 & 0.095 & 0.443 & 1.067 \\ 0.632 & 0.073 & 0.383 & 1.043 \\ 0.756 & 0.166 & 0.51 & 1.123\end{array}$

No significant difference between age and \% testing positive for any STI: $X 2=4.613, p=0.594$

\begin{tabular}{|c|c|c|c|c|c|c|}
\hline Non-student & 2064 & $26 \%$ & 1.553 & $0.001^{\mathrm{a}}$ & 1.193 & 2.021 \\
\hline Student ${ }^{R}$ & 716 & $18 \%$ & & & & \\
\hline \multicolumn{7}{|c|}{ Significant difference between student status and \% testing positive for any STI: $X 2=18.580, p<0.0005$} \\
\hline Heterosexual & 2649 & $24 \%$ & 1.097 & 0.674 & 0.712 & 1.692 \\
\hline Other ${ }^{R}$ & 131 & $22 \%$ & & & & \\
\hline \multicolumn{7}{|c|}{ No significant difference between sexual orientation and \% testing positive for any STI: $\mathrm{X} 2=0.332, p=0.323$} \\
\hline White & 2706 & $24 \%$ & 0.808 & 0.458 & 0.46 & 1.419 \\
\hline Black/minority/ethnic ${ }^{R}$ & 74 & $23 \%$ & & & & \\
\hline \multicolumn{7}{|c|}{ No significant difference between sexual orientation and \% testing positive for any STI: $x 2=0.067, p=0.461$} \\
\hline Deprivation quintile 1 & 357 & $28 \%$ & 1.473 & $0.018^{\mathrm{b}}$ & 1.067 & 2.033 \\
\hline Deprivation quintile 2 & 553 & $28 \%$ & 1.495 & $0.006^{\mathrm{a}}$ & 1.12 & 1.995 \\
\hline Deprivation quintile 3 & 609 & $27 \%$ & 1.462 & $0.008^{\mathrm{a}}$ & 1.103 & 1.937 \\
\hline Deprivation quintile 4 & 435 & $25 \%$ & 1.389 & $0.033^{b}$ & 1.027 & 1.879 \\
\hline
\end{tabular}

Deprivation quintile $5^{R} \quad 789 \quad 18 \%$

Significant difference between deprivation status and \% testing positive for any STI: $X 2=24.255, p<0.0005$

Low risk $k^{R} \quad 1568 \quad 24 \%$

Increasing risk $\quad 1034 \quad 24 \%$

Higher risk $\quad 109 \quad 23 \%$

Probable dependence $\quad 69 \quad 38 \%$

\begin{tabular}{|c|c|c|c|c|}
\hline $4 \%$ & 1.03 & 0.761 & 0.85 & 1.249 \\
\hline $3 \%$ & 0.92 & 0.73 & 0.574 & 1.476 \\
\hline $8 \%$ & 1.7 & $0.041^{b}$ & 1.021 & 2.83 \\
\hline
\end{tabular}

No significant difference between risk status and \% testing positive for any STI: $X 2=7.116, p=0.068$

Total 2780 $24 \%$

$\mathrm{R}$ - reference group

a - significant at $99 \%$ level

b - significant at $95 \%$ level

intervention. The likelihood of being offered a BI was only significant for different drinking risk groups and not for any other demographic factors which suggests that sexual health practitioners were not biased by demography in their alcohol screening and delivery of BIs.

Efficacy to the intervention was not assessed in this current study, nevertheless over half of the patients who scored positive on the AUDIT (53\%) were recorded as been offered a BI. Furthermore, we did find that those identified as requiring a referral onto specialist treatment for their alcohol use were identified by the clinical staff and provided with the opportunity to access treatment they may not have otherwise received. Although these numbers are low, they are higher than has been found in other settings [35] and provided the opportunity for sexual health professionals to intervene early for hazardous and harmful drinkers.

When analysing the relationship between different demographic groups with a positive diagnosis of an STI, it was non-students, those living in the four least deprived 
quintiles and those scoring as probably dependent on AUDIT who were significantly more likely to be diagnosed with an STI. As a result there is an argument for undertaking screening with these groups in order to attempt to reduce a patient's level of alcohol consumption and the subsequent risk of contracting another STI in the future.

Crawford, et al. (2015) examined the clinical and costeffectiveness of alcohol screening and BI in three sexual health clinics in London, UK. The two arm trial randomized 802 patients to either brief intervention or an advice leaflet on health and lifestyle. The adjusted mean difference in alcohol consumption at 6 months was not significantly different at -2.33 units per week $(95 \%$ CI -4.69 to $0.03, p=0.053$ ) among those in the brief intervention group compared to the control arm (treatment as usual) of the trial. Unprotected sex was significantly reduced in both groups with 154 (53\%) of those who received brief advice, and 178 (59\%) in the control group (adjusted OR $=0.89,95 \%$ CI 0.63 to $1.25, p=0.496$ ) [36]. However alcohol use in both groups did reduce between baseline and follow-up as did levels of unprotected sex. Similar findings in alcohol use have been found in other studies where leaflets are given as part of the control condition [29].

Therefore the question remains should alcohol screening and BI occur in this setting? To answer this question further research is needed however we believe this present study shows that it is possible to embed alcohol screening as part of routine practice by sexual health staff. As substance use is a core part of clinical assessments within GUM it is appropriate to use an existing evidence based tool. Additionally, as demonstrated in this study, with the patient self-completing the AUDIT in advance of the clinical assessment it reduces the time burden for staff. The GUM clinics involved are continuing to screen using AUDIT as part of their clinical assessment, provide BI and record this, however more work is needed to ensure everyone who screens positive are both offered and provided with an intervention.

The findings also add more depth to the literature on the levels of alcohol consumption amongst patients attending sexual health services by identifying more specific population groups who may be more at risk of risky drinking; as well as probable dependent drinkers who are more likely to also be diagnosed with an STI. Therefore sexual health services may benefit from targeted as opposed to universal screening, particularly if resources are scarce.

However this study does have limitations. The study was undertaken in one GUM service in the North East of England and therefore findings may not be generalizable to other areas. The AUDIT is a validated tool [21], however efficacy of BI in this setting has not been ascertained (and was not an objective of this study). Training did take place in how to use the AUDIT however it is a self-report measure and we cannot be sure the patients were truthful in completing the questionnaire. We did not carry out any qualitative work and only used recorded data; therefore cannot confirm whether the recording of a BI actually meant it took place or whether those that were referred to alcohol treatment services actually attended.

\section{Conclusion}

This present study shows that it is possible to embed alcohol screening into routine practice in GUM clinics as part of clinical assessment; promoting the use of an evidence based tool and establishing pathways of care between sexual health and alcohol treatment services. However, further work is required to ascertain efficacy of $\mathrm{BI}$ in this setting in order to advocate for its use as either a universal or targeted public health intervention.

\section{Abbreviations \\ AUDIT: Alcohol Use Disorder Identification Test; BI: Brief Intervention; \\ Cl: Confidence interval; GUM: Genitourinary medicine; NHS: National health service; NICE: National Institute for health and care excellence; or: Odds ratio; STI: Sexually transmitted infection; UK: United Kingdom}

\section{Acknowledgements \\ The authors acknowledge the help and support of Dr. Tim Rapley and Dr. Sally Brown who are co-supervisors of Claire Sullivan's PhD research (alongside Professor Dorothy Newbury-Birch).}

\section{Funding}

No funding was available for this work.

\section{Availability of data and materials}

The raw data is owned by NHS County Durham and Darlington Foundation Trust and is not available.

\section{Authors contributions}

CS instigated the study. CW was the medical advisor in the study site. NM carried out the statistical analysis. CS and DNB wrote the first draft of the manuscript. All authors agreed the final version of the manuscript.

\section{Ethics approval and consent to participate}

The study was identified in the annual audit cycle for the service. The clinical governance department provided approval for the audit protocol and we received permission from the Head of Sexual Health for the use of the data. As is was part of the annual audit cycle, NHS ethics was not required. All patients on entering the service completed a consent form that included a section on the use of anonymised patient data by clinic staff for audit and research purposes. Only Trust staff had access to patient level data. A multi-disciplinary steering group provided oversight and performed a scrutiny role for the study.

\section{Consent for publication}

Not applicable.

\section{Competing interests}

There are no competing interests.

\section{Publisher's Note}

Springer Nature remains neutral with regard to jurisdictional claims in published maps and institutional affiliations.

\section{Author details}

${ }^{1}$ Public Health England, North East Centre, Newcastle upon Tyne, UK.

${ }^{2}$ Institute of Health \& Society, Newcastle University, Newcastle upon Tyne, 
UK. ${ }^{3}$ Balance, North East Alcohol Office, Durham, UK. ${ }^{4}$ County Durham and Darlington NHS Foundation Trust, County Durham, UK. ${ }^{5}$ School of Health and Social Care, Teesside University, Constantine Building, Middlesbrough TS1 3BA, UK

\section{Received: 17 May 2016 Accepted: 26 October 2017}

Published online: 17 November 2017

\section{References}

1. HM Government. The Government's alcohol strategy. London: HM Stationery Office; 2012

2. Rehm J, Mathers C, Popova S, Thavorncharoensap M, Teerawattananon Y, Patra J. Global burden of disease and injury and economic cost attributable to alcohol use and alcohol-use disorders. Lancet. 2009;373:2233.

3. Saunders J. N. L: hazardous alcohol use disorder, and approaches to its diagnosis and management. Compr Psychiatry. 2000;41(2):95-103.

4. World Health Organisation. International classification of diseases (10th revision). Geneva: W.H.O; 1992

5. Zenilman J, Hook E, Shepherd M, Smith P, Rompalo A, Celentano D. Alcoho and other substance use in STD clinic patients: relationships with STDs and prevalent HIV infection. Sex Transm Dis. 1994;21(4):220-5.

6. Coleman L, Cater S. A qualitative study of the relationship between alcohol consumption and risky sex in adolescents. Arch Sex Behav. 2005;34(6):649-61.

7. Sumnall H, Beynon C, Conchie S, Riley S, Cole J. An investigation of the subjective experiences of sex after alcohol or drug intoxication. J Psychopharmacol. 2007:21:527-37.

8. Bellis MA, Hughes K, Calafat A, Juan M, Ramon A, Rodriguez JA, Mendes F, Schnitzer S, Phillips-Howard P, Bellis MA, et al. Sexual uses of alcohol and drugs and the associated health risks: a cross sectional study of young people in nine European cities. BMC Public Health. 2008:8:155.

9. George W, Davis K, Norris J, Heiman J, Stoner S, et al. Indirect effects of acute alcohol intoxication on sexual risk-taking: the roles of subjective and physiological sexual arousal. Arch Sex Behav. 2009;38:498-513.

10. George W, Stoner S. Understanding acute alcohol effects on sexual behaviour. Annual Review of Sex Research. 2000;11:92-124.

11. Norris A, Kitali A, Worby E. Alcohol and transexual sex: how risky is the mix? Soc Sci Med. 2009:69:1167-76.

12. Abbey A, Saenz C, Buck P. The cumulative effects of acute alcohol consumption, individual differences and situational perceptions on sexual decision making. Journal of Studies of Alcohol. 2005;66(1):82-90.

13. Cooper L. Alcohol use and risky sexual behaviour among college students and youth; evaluating the evidence. J Stud Alcohol Suppl. 2002;(No 14):101-117.

14. Cook R, Clark D. Is there an association between alcohol consumption and sexually Tansmitted diseases? A systematic review. Sex Transm Dis. 2005; 32(3):156-64.

15. Standerwick K, Davies C, Tucker L, Sheron N. Binge drinking, sexual behaviour and sexually transmitted infection in the UK. Int J STD AIDS. 2007; 18(12):810-3.

16. Crawford MJ, Lowe PC, Greene L, Brookings $C$. The prevalence of excessive alcohol consumption and the acceptability of brief advice in a sexual health clinic: cross sectional survey. Sex Transm Infect. 2004;80(5):416-7.

17. Abbey A, Zawacki T, O'Buck P, Clinton A, McAuslan P. Sexual assault and alcohol consumption: what do we know about their relationship and what types of reserach are still needed? Aggress Violent Behav. 2004;9(3):271-303.

18. Graves $\mathrm{K}$, Leigh $\mathrm{B}$. The relationship of substance use to sexual activity among young adults in the United States. Family Planning Perspective. 1995:27(1):18-22.

19. Leigh B, Stall R. Substance use and risky sexual behavior for exposure to HIV. Issues in methodology, interpretation, and prevention. Am Psychol. 1993;48(10):1035-45

20. Kaner E, Beyer F, Dickinson H, Pienaar E, Campbell F, Schlesinger C, Heather $\mathrm{N}$, Saunders J, Burnand B. Effectiveness of brief alcohol interventions in primary care populations. Cochrane Database Syst Rev. 2007;Issue 2 CD004148.DOI:004110.001002/14651858.CD14654148.pub14651853

21. Saunders JB, Aasland OG, Babor TF, De La Fuente JR, Grant M. Development of the alcohol use disorders identification test (AUDIT): WHO collaborative project on early detection of persons with harmful alcohol consumption. Addiction. 1993:88(6):791-804.

22. National Institute for Health and Clinical Excellence: Alcohol-use disorders - preventing the development of hazardous and harmful drinking. http://guidance.nice.org.uk/PH24 2010.
23. Miller W, Rollnick S. Motivational interviewing; preparing people to change addictive behavior. New York: Guildford Press; 1991.

24. Babor T. Avoiding the horrid and beastly sin of drunkenness: does dissuasion make a difference? J Consult Clin Psychol. 1994;62(6):1127-40.

25. Heather N. A long-standing World Health Organization collaborative project on early identification and brief alcohol intervention in primary health care comes to an end. Addiction. 2007;102:679-81.

26. Funk M, Wutzke S, Kaner E, Anderson P, Pas L, McCormick R, Gual A, Barfod S. A multi country controlled trial of strategies to promote dissemination and implementation of brief alcohol intervention in primary health care: findings of a WHO collaborative study. J Stud Alcohol. 2005:66:379-88.

27. Holloway AS, Watson HE, Arthur AJ, Starr G, McFadyen AK, McIntosh J. The effect of brief interventions of alcohol consumption among heavy driners in a general hospital setting. Addiction. 2007;102:1762-70.

28. Brown S, Henderson E, Sullivan C. The feasibility and acceptability of the provision of alcohol screening and brief advice in pharmacies for women accessing emergency contraception: an evaluation study. BMC Public Health. 2014;14(1):1139.

29. Kaner E, Bland M, Cassidy P, Coulton S, Dale V, Deluca P, Gilvarry E, Godfrey $C$, Heather N, Myles J, et al. Effectiveness of screening and brief alcohol intervention in primary care (SIPS trial): pragmatic cluster randomised controlled trial. BMJ. 2013;346

30. Drummond C, Deluca P, Coulton S, Bland M, Cassidy P, Crawford M, Dale V, Gilvarry E, Godfrey C, Heather N, et al. The effectiveness of alcohol screening and brief intervention in emergency departments: a multicentre pragmatic cluster randomized controlled trial. PLoS One. 2014;9(6):e99463.

31. Hodgson R, Alwyn T, John B, Thom B, Smith A. The FAST alcohol screening test. Alcohol \& Alcoholism. 2002;37(1):61-6.

32. National statistics - postcode [data.gov.uk/dataset/national-statisticspostcode-lookup-uk]. Accessed 1 Apr 2016.

33. English Indices of deprivation 2010 [http://www.gov.uk/government/ statistics/english-indices-of-deprivation-2010]. Accessed 1 Apr 2016.

34. North West Public Health Observatory. Topography of drinking Behaviours in England. Synthetic estimates of numbers and proportions of abstainers, lower risk, increasing risk and higher risk drinkers in local authorities in England. In: Liverpool JMU Centre for public health; 2011.

35. O'Donnell A, Kaner E, Newbury-Birch D, Schulte B, Schmidt C, Reimer J, Anderson $P$. The impact of brief interventions in primary healthcare: a systematic review of reviews. Alcohol Alcohol. 2014;49(1):66-78.

36. Crawford M, Sanatinia R, Barrett B, Byford S, Dean M, Green J, Jones R, Leurent $B$, Sweeting M, Touquet $R$, et al. The clinical and cost-effectiveness of brief advice for excessive alcohol consumption among people attending sexual health clinics: a randomised controlled trial. Sex Transm Infect. 2015;91:37-43.

\section{Submit your next manuscript to BioMed Central and we will help you at every step:}

- We accept pre-submission inquiries

- Our selector tool helps you to find the most relevant journal

- We provide round the clock customer support

- Convenient online submission

- Thorough peer review

- Inclusion in PubMed and all major indexing services

- Maximum visibility for your research

Submit your manuscript at www.biomedcentral.com/submit 